\section{Las arañas sinantrópicas peligrosas de Chile}

\section{Synantropic dangerous spiders from Chile}

\section{Sr. Editor:}

Todas las arañas, excepto los miembros de la familia Uloboridae, son ponzoñosas, es decir producen sustancias tóxicas ${ }^{1}$. Sin embargo, sólo unas pocas especies pueden ser consideradas peligrosas para el ser humano. Son consideradas arañas peligrosas todas las que: a) poseen un veneno con actividad patógena para el ser humano; b) viven donde éste habita o desarrolla sus actividades; y c) tienen los extremos anteriores de los quelíceros, finos y poderosos, que les permiten perforar la piel e inyectar su veneno ${ }^{2}$.

Para Chile, previamente se han señalado como arañas peligrosas a las especies pertenecientes a los géneros Loxosceles, Latrodectus y Lycosa $a^{3}$; sin embargo, existen otros géneros, como Steatoda y Sicarius, que también han sido considerados posteriormente como peligrosos ${ }^{1}$. Además de la peligrosidad que puede conllevar la introducción de arañas foráneas de reconocido peligro, como el caso de Phoneutria sp. ${ }^{3}$.

De todas las especies peligrosas en Chile, únicamente Loxosceles laeta (Sicariidae) (Nicolet, 1849) y Steatoda grossa (Theridiidae) (C. L. Koch, 1838) son arañas sinantrópicas o asociadas estrechamente con las viviendas humanas ${ }^{1,2,5} \mathrm{y}$, por tanto, las que podrían conllevar el mayor riesgo para las personas. Paradójicamente, son precisamente las arañas sinantrópicas las que han sido menos estudiadas, dejando un gran vacío respecto a las especies potencialmente peligrosas que conviven con el ser humano en ambientes urbanos.

En base a la literatura consultada, se consideran dos familias de arañas peligrosas de naturaleza sinantrópica para Chile: Sicariidae y Theridiidae. En Chile, estas familias se encuentran representadas por cuatro especies; Loxosceles laeta, Latrodectus geometricus y Steatoda grossa $a^{1,2,6}$. Los hábitat usuales para estos arácnidos incluyen tanto las habitaciones al interior de las viviendas (sector domiciliario), como los jardines y antejardines de las viviendas (sector peridomiciliario).

Las arañas del género Latrodectus poseen un poderoso efecto neurotóxico y pueden generar en humanos calambres, sudoración profusa, dolores musculares, náuseas, vómitos, hipertensión y, en casos raros, la muerte del individuo, siendo este cuadro clínico conocido como latrodectismo. En Chile, es sabido que la Latrodectus que habita en territorio nacional ("viuda negra") es predominantemente rural y su hábitat está básicamente constituido por campos de cultivo de trigo, alfalfa y lino, y por diversas especies vegetales, troncos de árboles y rocas ${ }^{2}$. Sin embargo, L. geometricus, llamada vulgarmente como "viuda marrón" es una especie recientemente reportada para Chile (introducida) y estrictamente urbana, encontrándose frecuentemente en los jardines y antejardines de las casas. Los efectos de su mordedura son considerados de menor peligrosidad que la "viuda negra"; sin embargo, en algunos casos podrían a llegar a ser graves, lo que la hace especialmente peligrosa, dado su mayor contacto con las personas ${ }^{6}$.

Respecto a las arañas del género Steatoda, conocidas vulgarmente como "falsas viudas" y cuya mordedura es causante del cuadro clínico denominado "steatodismo", no existen reportes oficiales de su mordedura en Chile; sin embargo, en otros países el cuadro clínico producido por su mordedura es considerada de importancia médica, ya que el efecto de su veneno es muy parecido a los síntomas provocados por el latrodectismo ${ }^{1,4}$. Los efectos provocados por las mordeduras de especies como S. grossa han sido debidamente documentados en países como Australia, caracterizando a estas especies como peligrosas para el ser humano ${ }^{4}$.

Por último, la especie L. laeta, conocida vulgarmente como "araña violinista" o "araña de los rincones", es otra de las especies fanerotóxicas encontradas en las viviendas. Su veneno tiene un potente efecto dermonecrótico, vasculítico, hemolítico y coagulante, y su mordedura es causante del cuadro clínico denominado loxoscelismo ${ }^{3}$, el cual ha sido debidamente documentado en la literatura médica.

Conclusiones: 1) Existirían tres géneros de arañas cuyas mordeduras podrían ser consideradas relevantes y se encuentran en las casas: Loxosceles, Latrodectus y Steatoda, cada una de ellas causante de tres cuadros epidemiológicos distintos, denominados respectivamente como loxoscelismo, latrodectismo y steatodismo; 2) En Chile, son necesarios estudios futuros para clarificar si existen o no otras especies potencialmente peligrosas, sobre todo en aquellos lugares históricamente pocos explorados, como el extremo norte y sur del país; 3) Se deben tomar medidas adecuadas para evitar la introducción de arañas potencialmente 
peligrosas y de las cuales no se disponen antídotos; 4) Concordando con estudios anteriores, se insta a que el paciente que ha sufrido una mordedura, al consultar traiga la araña o sus fragmentos para una adecuada determinación de la especie de araña, la cual debe ser realizada por un especialista en la materia.

$$
\begin{array}{r}
\text { Andrés Taucare-Ríos } \\
\text { Centro de Investigación del Medio } \\
\text { Ambiente (CENIMA), Universidad Arturo } \\
\text { Prat, Iquique, Chile. }
\end{array}
$$

\section{Referencias}

1. Faúndez EI. Arañas (Arachnida: Araneae) peligrosas de la región de Magallanes. An Inst Patagon 2009; 37 (1): 127-31.
2. Schenone H. Cuadros tóxicos producidos por mordedura de araña en Chile: latrodectismo y loxoscelismo. Rev Med Chile 2003. 131: 437-44.

3. Canals M, Casanueva ME, Aguilera M. ¿Cuáles son las arañas peligrosas de Chile?. Rev Med Chile 2004; 132: 773-6.

4. Braitberg G, Segal L. Spider bites-Assessment and management. Aust Fam Physician 2009; 38 (11): 862-7.

5. Taucare-Ríos, A. Nuevo registro de Steatoda grossa (C.L Koch, 1838) (Araneae: Theridiidae) para la región de Tarapacá, Chile. Bol Biodivers Chile 2010; 4: 87-9.

6. Taucare-Ríos A. Primer registro de la viuda marrón, $L a$ trodectus geometricus Koch, 1841 (Araneae: Theridiidae) en el Norte de Chile. Rev Chil Entomol 2011; 36: 39-42.

Correspondencia a:

Sr. Andrés Taucare-Ríos, Casilla 121, Iquique, Chile. E-mail: and. taucare22@gmail.com 